\title{
Knowledge and Practices of Agricultural Extension Officers in Management of the Invasive Tuta Absoluta Meyerick (Gelechiidae) in Tanzania
}

\author{
Maneno Chidege ${ }^{1}$, Secilia Mrosso ${ }^{2}$, Christopher L. Materu ${ }^{3}$ \\ ${ }^{1,2}$ Tropical Pesticide Research Institute P. O. Box. 3024, Arusha, Tanzania \\ ${ }^{3}$ Mikocheni Agricultural Research Institute, P. O. Box. 6226, Tanzania
}

\begin{abstract}
Tomato leaf miner is native pest of South America and one of the most serious pest of tomato (Solanum lycopersicum) and solanaceous plants. In Tanzania tomato is one of the most important nutritious vegetable crop and source of income (FAO 2012). Training of agricultural extension officers on sustainable management of invasive species like Tuta absoluta, especially training of trainers (ToTs) is crucial to equip them with adequate and appropriate knowledge about the pest. The report was developed during T. absoluta workshop held at TPRI in July 21, 2015 where by a total of 100 extension officers from three regions namely (Arusha, Kilimanyaro and Manyara) of northern Tanzania were randomly interviewed to assess their knowledge and practices on management of T. absoluta. The results revealed that (85\%) of the respondents were aware of the T. absoluta as a major problem in most tomato growing areas. Additionally, of the total respondents (90\%) indicated poor knowledge on identification, detection and management. Therefore, the need for TOT training to extension officers was a sustainable mitigation measures to manage T. absoluta in tomato growing areas.
\end{abstract}

Keywords: Extension officer, Knowledge, Leaf miner

\section{Introduction}

In Tanzania tomato (Lycopersicon esculentum Mill. or Solanum lycopersicum $L$ ) is one of the most important edible and nutritious vegetable crop and source of income [4]. Tomato is produced by small and medium growers for home consumption and as a source of income. Tomato yield in Tanzania is estimated at $17.5 \mathrm{Mt} / \mathrm{ha}$. Currently yield production has dropped to $50 \%$ of the total production due to various constraints including pests and diseases [1].

The tomato leafminer, Tuta absoluta (Meyrick) (Lepidoptera: Gelechiidae) is one of the most serious pest of tomato (Solanum lycopersicum L.; Solanales: Solanaceae) but also known to attack cultivated solanaceous plants such as eggplant (Solanum melongena L.; Solanaceae), potato (Solanum tuberosum L.; Solanaceae), pepper (Capsicum annuиm L.; Solanaceae), tobacco (Nicotiana tabacum L.; Solanaceae), solanaceous weeds and garden bean (Phaseolus vulgaris L.; Fabales: Fabaceae) [4]. T. absoluta is a native pest of South America but has been spreading in Africa, Asia and Central America. Since its introduction to Spain in 2006, it has invaded most of the countries in Europe, Mediterranean, Middle East, Northern, western and eastern Africa, and India in South Asia [7] and [8]. In northern Africa, it was reported in Tunisia in 2008 [5], north of the Sahel in 2008 [7], Western Africa in 2010, Sudan and Ethiopia in 2011 [2]. It causes 80 to $100 \%$ crop loss unless proper management technologies are taken up [6]. The pest can breed between 10-12 generations a year and each female can lay 250-300 eggs in her life time [10] and [7]. There are 4 larval instars and the first 2 instars mine the leaves by feeding on the Mesophyll and leaving the epidermis intact. These mines reduce the photosynthetic surface of the leaves and result in early drying. Later instars larvae leave the mines and bore into stalks, apical buds, and fruits. It pupates in the mines, dried leaves or in soil [7] and [8].

\section{Materials \& Methods}

Knowledge and practices of agricultural extension officers against $T$. absoluta was assessed using semi structured open and close ended questionnaires. In a simple random sampling extension/officers from three regions (Arusha, Kilimanjaro and Manyara) of Northern Tanzania where tomato is one of the source of income were involved in the study. The study aimed at assessing knowledge and practices in management of T. absoluta whereby, the questioners were administered to enquire their understanding based on identification, detection and management practices against T. absoluta in the country. Additionally respondents were required to avail information on tomato farming practices, key pests and diseases in their home regions.

\subsection{Data Collection Procedure}

A semi-structured opened and close ended questionnaire was developed to address intended objectives of this study. The questionnaire was designed to collect information on general background of their regions and their knowledge on pesticide use for management of different pest species, knowledge on the identification of the pest and existing control measures against T. absoluta. The questionnaire was first developed and pre-tested aimed to improve the questionnaire. Pilot-testing of the questionnaire was useful as unwanted and long preliminary information collected from pre-tested information was not included in the main data used for the statistical analysis. 


\subsection{Data Analysis}

Data analysis was conducted with SPSS software version 11 for windows. Frequency distribution and percentages were used to describe the findings according to each specific research question. Preliminary data from this study were not included in the final data for analysis

\section{Results and Discussions}

The result revealed that ( $85 \%)$ of respondents were aware of damage caused by the invasive insect species in tomato fruits and leaves but not other plant parts like calyx whereas $(15 \%)$ are quit unaware of the damage inflicted by this pest species (Figure 1). In the same venture quit a number of total respondents $(95 \%)$ were unable to distinguish leaf damage caused by T. absoluta and that caused by other leaf miners such as; Liriomyze spp (Figure 2). More than (90\%) respondents indicated to have not known the adult moth of T. absoluta, and at what stage, which management measures can be applied. This is important for taxonomic and management purposes (Figure 2). Most of respondent indicated that, major control methods practiced in their regions were pesticides (95\%) (Figure 3). The results obtained from the study indicated inadequate/lack of knowledge of agricultural extension officers regarding the invasive tomato leaf miner, $T$. absoluta in the country. Training of extension staff is important as they can reach and access farmers easily and explain to them in a simple and user friend manner as most of tomato growers have low level of education [7] and [8]. Again the results revealed that, most of extension officers interviewed had BSc. degree $(60 \%)$ and Diploma (32\%) (Figure 4) implying the advantage of training of trainers (ToT) to this group of stakeholders.

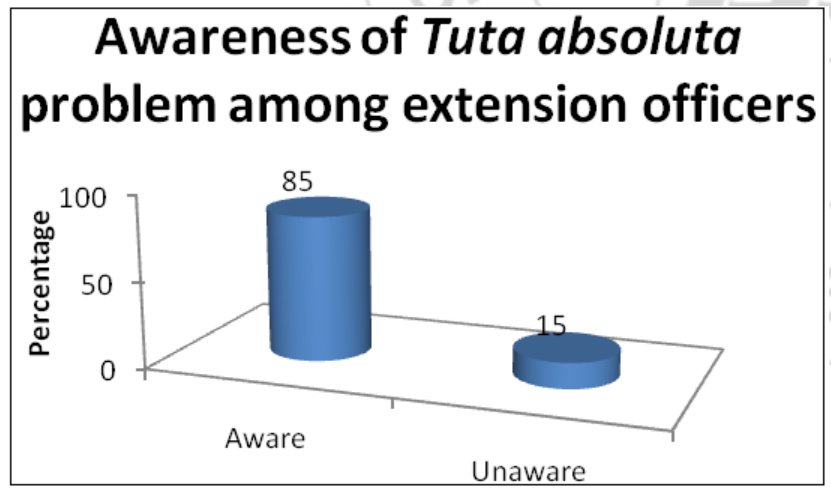

Figure 1: Percent proportion of the respondents awareness of T. absoluta problem in Tomato growers

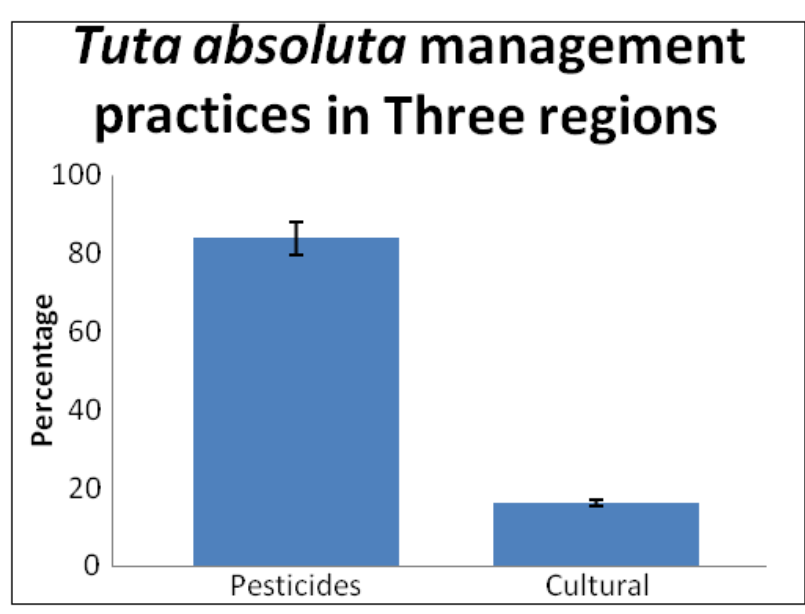

Figure 3: Percent proportion of the respondents on $T$. absoluta management practices.

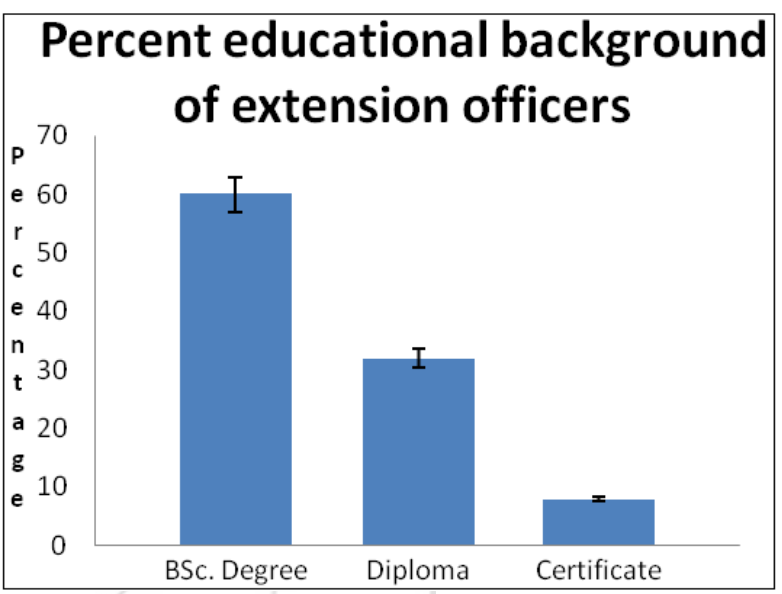

Figure 4: Percent educational background of respondents.

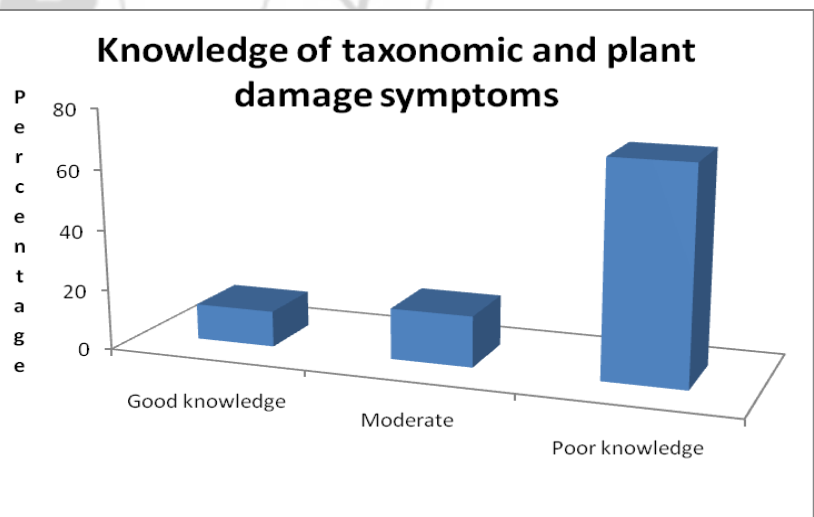

Figure 2: Taxonomic knowledge and plant damage symptoms

\section{Conclusion}

The invasion of T. absoluta in an area is detrimental if unchecked to the host county in both food security and safety due to economic losses and inappropriate pesticide usage respectively. Additionally loss of biodiversity is also possible due to effects of pesticides posed to pollinators and other beneficial terrestrial organisms. The information from this study realizes the need for capacity building and awareness creation by training of trainers (ToT) to agricultural extension officers. Major aspects such as, pest identification, destructive stages, damage symptoms and 


\section{International Journal of Science and Research (IJSR) \\ ISSN (Online): 2319-7064 \\ Index Copernicus Value (2013): 6.14 | Impact Factor (2015): 6.391}

different management options should be addressed in the training program. As stated by other authors [1] training and awareness creation of stakeholder is an important component in sustainable pest management. Through training innovations are brought to end users and upon usage, improvement of existing technologies can be made to suit the pest current situation.

There is therefore the need to carefully study how existing control practices can be improved upon, where necessary to enhance their effectiveness in $T$. absoluta suppression in tomato growing areas [9]. It is believed that more educated extension officers are better off positioned to acquire new scientific skills and knowledge from others sources to complement the existing practices and knowledge. There is therefore an urgent need to train extension workers on identification, detection and integrated pest management against $T$. absoluta using training of trainers (ToT) approach in the country.

\section{Acknowledgements}

Authors would like to acknoledge TPRI for infrastructure and administrative support. Many thanks are extended to IPM IL, Dr. Muniapan Rangswamy (The Director) for organizing and facilitating Tuta absoluta workshop at TPRI, it is this workshop which brought about 100 extension officers from northern zone of the country. Nevertheless, we are also thankful to USAID under feed the future program for financing the workshop.

\section{References}

[1] C. Materu, E. Shao, E. Losujaki, M. Chidege, N Mwambela (2016), Farmer's Perception Knowledge and Practices on Management of Tuta Absoluta Meyerick (Lepidotera Gelechiidae) in Tomato Growing Areas in Tanzania, International Journal of Research in Agriculture and Forestry, Volume 3, Issue 2, PP 1-5.

[2] D. Pfeiffer, R. Muniappan, D. Sall, P. Diatta, A. Diongue and E. Dieng (2013) First Record of Tuta absoluta (Lepidoptera: Gelechiidae) in Senegal. Florida Entomologist, 96(2):661-662.

[3] EPPO (2007). EPPO Plant quarantine data retrieval system. PQR version 4.6. http://www.eppo.org/DATABASES/pqr/pqr.htm

[4] Food and Agriculture Organization (2012) Growing greener cities in Africa First status in peri-urban Horticulture in Africa. Food and Agriculture the United Nations, Rome, Italy.

[5] K. Abbes, and B. Chermiti. (2014). Susceptibility of three Tunisian populations of the tomato leafminer Tuta absoluta (Lepidoptera: Gelechiidae) for deuterotokous parthenogenetic reproduction. Afr. Entomol. 22: 538544.

[6] L. Giulianotti, (2010): Certis IPM programme for the control of Tuta absoluta. International Pest Control, 52: 162-165.

[7] N. Desneux, E. Wajinberg, K. Wyckhuys, G. Burgio, S. Arpaia, C.A. Narvaez-Vasquez, J. Gonzalez-Cabrera, D. Catalan Ruescas, E. Tabone, J. Frandon (2010). Biological invasion of European tomato crops by Tuta absoluta: ecology, geographic expansion and prospects for biological control. J. Pest Sci. 83: 197-215.

[8] N. Desneux, M. Luna, T. Guillemaud and A Urbaneja, (2011). The invasive South American tomato pinworm,Tuta absoluta, continues to spread in AfroEurasia and beyond: the new threat to tomato world production. Journal of Pest Science 84: 403-408.

[9] N. Desneux, E. Wajnberg, K. Wyckhuys, G. Burgio, S. Arpaia, C. Narváez-Vasquez, J. González-Cabrera, D. Catalán Ruescas, E. Tabone, J. Frandon, J. Pizzol, C. Poncet, T. Cabello, A. Urbaneja, (2010): Biological invasion of European tomato crops by Tuta absoluta: ecology, geographic expansion and prospects for biological control, Journal of Pest Science 83 (3): 197 215.

[10] S. Ekesi and M.K.Billlah, (2006). A field guide to the management of economically important tephritid fruit flies in Africa. $2^{\text {nd }}$ edition. ICIPE Science Press ISBN: 92-9064-1797, Nairobi, Kenya, 115 pp.

[11]Z. Barrientos, H.J. Apablaza, S.A. Norero, P.P. Estay (1998): Threshold temperature and thermal constant for development of the South American tomato moth, Tuta absoluta (Lepidoptera, Gelechiidae), Ciencia e Investigacion Agraria 25, 133-137.

\section{Author Profile}

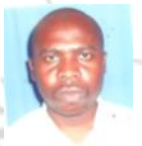

Maneno Yoram Chidege, received his BSc. Agriculture general in 2005 at Sokoine University of Agriculture, Tanzania. MSc. Crop science (Major in plant protection) in 2013 at Sokoine University of Agriculture, Tanzania. Currently working with Tropical Pesticides Research Institute as Plant Entomologist. 